\title{
Analisis Faktor yang Memengaruhi Implementasi Pendidikan Cerdas dalam Sistem Pemerintahan Berbasis Elektronik
}

\author{
Wendy Nur Falaq ${ }^{1}$, Dana Indra Sensuse ${ }^{2}$ \\ 1,2Magister Teknologi Informasi, Fakultas IImu Komputer, Universitas Indonesia \\ *wendy.nur@ui.ac.id
}

\begin{abstract}
Abstrak
Kemajuan pendidikan suatu daerah ditentukan oleh cara pemerintah dalam mengelola sistem pendidikannya. Smart education merupakan implementasi dari Sistem Pemerintahan Berbasis Elektronik (SPBE) berupa sistem pembelajaran yang memanfaatkan keterampilan abad-21 dengan dukungan infrastruktur $\mathrm{TI}$ yang mengikuti inovasi tren teknologi terbaru. Penerapan smart education sangat dibutuhkan terutama di masa pandemi dan pasca pandemi covid-19 untuk meningkatkan kualitas mutu pendidikan yang menurun sejak awal pandemi, namun belum semua daerah di Indonesia mampu dan siap dalam mengimplementasikan konsep tersebut. Pemerintah daerah terutama yang sudah menerapkan smart city membutuhkan suatu referensi terkait faktorfaktor yang perlu diperhatikan dalam implementasi smart education untuk menghindari risiko kegagalan. Berdasarkan masalah tersebut, tujuan dari penelitian ini adalah membuat suatu rangkuman mengenai faktor apa saja yang perlu diperhatikan untuk menunjang keberhasilan implementasi smart education. Penelitian ini memanfaatkan metode systematic literature review untuk mengidentifikasi faktor-faktor yang menjadi tantangan dan perlu diperhatikan dalam implementasi smart education berdasarkan penelitian-penelitian yang pernah dilakukan sebelumnya. Penelitian menghasilkan 5 aspek utama yang merupakan ringkasan semua faktor yang ditemukan dari penelitian sebelumnya, yaitu aspek teknologi, aspek data, aspek sumber daya manusia, aspek tata kelola, dan aspek pembiayaan. Semua faktor dari 5 aspek tersebut harus diperhatikan oleh pemerintah dan pihak terkait untuk meningkatkan kesuksesan implementasi smart education.
\end{abstract}

Kata kunci: spbe, e-government, smart city, smart education, pembelajaran cerdas

\begin{abstract}
The improvement of education in an area is determined by the government's method of managing its education system. Smart education is an implementation of e-Government in a learning system that uses 21 st century skills with the support of IT infrastructure and implementing the latest technological innovations. The implementation of smart education is required, especially during the pandemic and post-pandemic to improve the quality of education which has declined since the beginning of covid-19 pandemic, but not all regions in Indonesia are able and ready to implement the concept. City/district governments, especially those that have implemented smart cities, need a reference regarding the factors that considered in implementing smart education to avoid the risk of failure. Based on these problems, the purpose of this study is to create a summary of the factors that need to be considered to increase the success of smart education implementation. This study uses a systematic literature review method to identify factors that are considered in implementing smart education based on previous studies. The research produces five main aspects which are a summary of all the factors found in previous studies, which consist of technological aspects, data aspects, human resources aspects, governance aspects, and financial aspects. All factors from these five aspects can be a reference for the government and related parties to increase the success rate of implementing smart education.
\end{abstract}

Keywords: e-government, smart city, smart education, smart learning, systematic literature review 


\section{Pendahuluan}

Pandemi covid-19 yang terjadi di hampir seluruh negara secara tidak langsung telah mengubah sistem pendidikan, yaitu terjadinya percepatan penerapan konsep smart education. Salah satu bentuk penerapannya adalah pembelajaran jarak jauh atau daring. Dilansir dari Katadata [1], studi tentang "Satu Tahun Pandemi" yang dilakukan Organisasi Pendidikan, Keilmuan, dan Budaya PBB (UNESCO) pada tahun 2021 telah menyimpulkan terjadinya penurunan potensi kemampuan membaca siswa selama pandemi covid-19.

Untuk mengatasi turunnya kualitas pendidikan selama masa pandemi dan setelah pandemi, konsep smart education harus dapat diimplementasikan dengan tepat dan sesuai sasaran. Sayangnya belum semua daerah di Indonesia siap mengimplementasikan konsep smart education karena transformasi yang dilakukan tidak hanya mengubah kurikulum dan cara belajar luring ke daring saja, tetapi terdapat banyak faktor yang perlu dipersiapkan. Pemerintah harus mengetahui faktor-faktor apa saja yang berpengaruh pada proses implementasi agar seluruh pihak yang terlibat lebih siap, transformasi berjalan lancar, dan risiko kegagalan dapat dihindari $[2,3]$.

Beberapa penelitian yang membahas implementasi smart education sudah pernah dilakukan baik di Indonesia maupun di wilayah lain yang memiliki beragam hasil. Keragaman hasil penelitian tersebut perlu dirangkum dalam suatu standar yang lebih mudah diacu oleh kota/kabupaten di Indonesia.

Berdasarkan latar belakang dan kajian literatur yang telah disebutkan, permasalahan yang dihadapi pemerintah daerah dan pihak terkait dalam penerapan smart education adalah dibutuhkannya suatu rangkuman referensi terkait faktor-faktor yang perlu diperhatikan agar implementasi berjalan sukses dan terhindar dari risiko kegagalan. Dari perumusan masalah tersebut, maka tujuan penelitian ini adalah membuat suatu rangkuman mengenai faktorfaktor apa saja yang perlu dipertimbangkan oleh pemerintah daerah dalam mengimplementasikan konsep smart education berdasarkan penelitianpenelitian yang pernah dilakukan sebelumnya menggunakan metodologi Systematic Literature Review (SLR). Diharapkan penelitian ini menjadi referensi bagi pemerintah dalam mengembangkan dan menerapkan smart education di wilayahnya.

\section{Tinjauan Pustaka}

E-Government atau sistem pemerintahan berbasis elektronik (SPBE) merupakan penyelenggaraan pemerintahan dengan memanfaatkan teknologi informasi dan komunikasi untuk memberikan layanan kepada 
pengguna [4]. Salah satu langkah implementasi e-Government adalah pengembangan smart city, khusus pada bidang pendidikan terdapat konsep smart education. Smart education merupakan suatu konsep pembelajaran yang memanfaatkan keterampilan abad-21, yakni berpusat pada peserta didik dengan dukungan infrastruktur $\mathrm{TI}$ tingkat lanjut dan terintegrasi sehingga proses pembelajaran berjalan interaktif, inovatif, dan komprehensif $[2,3,5]$. Kebaruan teknologi yang digunakan dalam proses dan pembuatan produk pembelajaran harus mampu memberikan kesempatan dan akses pendidikan yang layak bagi seluruh elemen masyarakat [3].

\section{Metode Penelitian}

Dalam menyajikan tinjauan literatur untuk mengidentifikasi faktor-faktor yang dapat mempengaruhi implementasi smart education, digunakan beberapa langkah metode SLR yang berpedoman pada penelitian Boell dan CecezKecmanovic [6].

Langkah metode SLR terdiri dari enam bagian, yaitu: 1) SLR Protocol, mendefinisikan pertanyaan penelitian, sumber pencarian, kondisi pencarian, strategi pencarian, kriteria khusus, maupun kriteria yang dihindari. 2) Search for Literature, melakukan pencarian literatur secara online pada beberapa portal sumber yang telah ditentukan sebelumnya. 3) Select Literature, Menyeleksi hasil pencarian literatur yang terkait dengan kata kunci pertanyaan penelitian. 4)

Summarize Evidence, Menyimpulkan isi dari semua literatur yang telah dipilih. 5) Disseminate Result, menuliskan hasil penelitian ke dalam sebuah laporan karya tulis. llustrasi langkah SLR dapat dilihat pada Gambar 1.

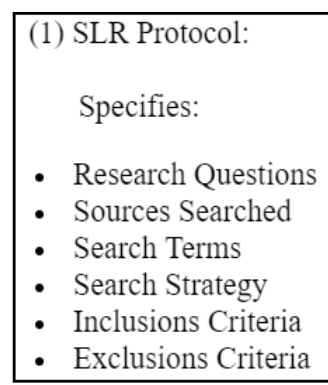

\section{Gambar 1. Ilustrasi Proses SLR pada Domain SI/TI [6]}

Proses awal yang dilakukan adalah tahap SLR Protocol dengan mendeskripsikan pertanyaan penelitian, pemilihan sumber pencarian literatur, mendeskripsikan istilah kunci pencarian, dan menyusun strategi pencarian literatur. Detail proses pada tahap SLR Protocol ini dapat dilihat pada Tabel 1.

Tabel 1. Protokol SLR

\begin{tabular}{|c|c|}
\hline Protokol & Deskripsi \\
\hline $\begin{array}{l}\text { Pertanyaan } \\
\text { Penelitian }\end{array}$ & $\begin{array}{l}\text { Faktor-faktor apa yang perlu } \\
\text { diperhatikan pemerintah daerah } \\
\text { dalam mengimplementasikan konsep } \\
\text { Smart Education? }\end{array}$ \\
\hline Sumber & $\begin{array}{ll}\text { - } & \text { ACM Digital Library } \\
& \text { (http://portal.acm.org) } \\
\text { - } & \text { IEEEXplore } \\
& \text { (http://ieeexplore.ieee.org) } \\
\text { - } & \text { MECS Press (http://www.mecs- } \\
& \text { press.org/) } \\
\text { - } & \text { Science Direct } \\
& \text { (http://www.sciencedirect.com) } \\
\text { - } & \text { SpringerLink } \\
& \text { (http://link.springer.com) } \\
\end{array}$ \\
\hline $\begin{array}{l}\text { Protokol } \\
\text { SLR }\end{array}$ & Deskripsi \\
\hline
\end{tabular}




\begin{tabular}{|c|c|}
\hline $\begin{array}{l}\text { Istilah } \\
\text { Pencarian }\end{array}$ & $\begin{array}{l}\text { ("Smart Education" OR "Smart } \\
\text { Learning") }\end{array}$ \\
\hline $\begin{array}{l}\text { Strategi } \\
\text { Pencarian }\end{array}$ & $\begin{array}{l}\text { - Langkah 1: Memasukkan kata } \\
\text { kunci ke dalam fitur pencarian di } \\
\text { portal perpustakaan digital. } \\
\text { Kemudian memilih tahun } \\
\text { publikasi antara tahun } 2016 \\
\text { hingga tahun } 2020 \text {. } \\
\text { - Langkah 2: Menyatakan total } \\
\text { hasil pencarian berdasarkan kata } \\
\text { kunci sebagai "paper ditemukan". } \\
\text { - Langkah 3: Membaca judul } \\
\text { setiap makalah yang ditemukan, } \\
\text { jika judul tidak dapat } \\
\text { mengidentifikasi isi makalah, } \\
\text { dilanjutkan membaca abstrak. } \\
\text { Jika judul dan abstrak selaras } \\
\text { dengan tujuan penelitian, maka } \\
\text { makalah akan diunduh untuk } \\
\text { penyelidikan lebih lanjut. } \\
\text { Makalah yang diunduh disebut } \\
\text { "paper kandidat". } \\
\text { Langkah 4: "paper kandidat" } \\
\text { akan dipelajari untuk melihat } \\
\text { relevansi dengan tujuan } \\
\text { penelitian. Makalah yang relevan } \\
\text { akan dikategorikan sebagai } \\
\text { "paper terpilih". }\end{array}$ \\
\hline
\end{tabular}

\section{Hasil dan Pembahasan}

Hasil pencarian pada lima portal sumber referensi dengan memasukkan kata kunci yang sesuai ditemukan sejumlah 553 paper atau makalah ilmiah. Makalah tersebut hanya yang dipublikasikan lima tahun terakhir antara tahun 2016 hingga tahun 2020 dan memiliki keterkaitan dengan Smart Education atau Smart Learning. Dari sebanyak 553 makalah yang ditemukan, didapatkan hasil 21 makalah terpilih dan terkait erat dengan bahasan penelitian. llustrasi proses pemilihan untuk menghasilkan data makalah terpilih ditunjukkan pada Gambar 2.

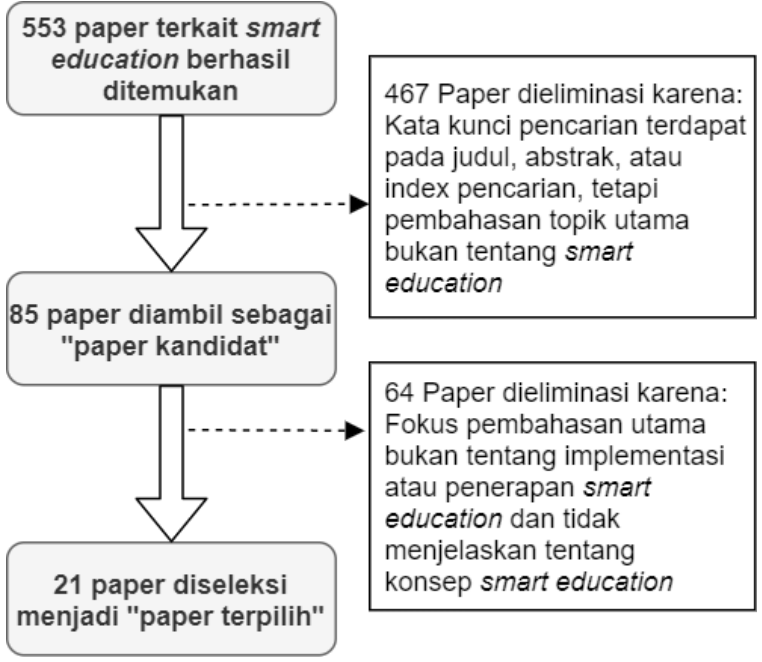

Gambar 2. Hasil Proses Pencarian Sumber Pustaka

Makalah ilmiah diambil melalui lima portal yang menyediakan akses ke sumber data makalah berkualitas, yaitu ACM Digital Library, IEEE Xplore, MECS Press, Science Direct, dan Springer Link. Dari sebanyak 553 makalah ilmiah, sebanyak 467 makalah dieliminasi karena kata kunci pencarian terdapat pada judul, abstrak, atau index pencarian, tetapi pembahasan topik utama bukan tentang smart education sehingga didapatkan 85 makalah kandidat. Kemudian 64 makalah dieliminasi karena fokus pembahasan utama bukan tentang implementasi atau penerapan smart education dan tidak menjelaskan tentang konsep smart education.

Jumlah hasil seleksi makalah dari portal sumber referensi ditunjukkan pada Tabel 2.

Tabel 2. Seleksi Data Hasil Pencarian

\begin{tabular}{cccc}
\hline Sumber & $\begin{array}{c}\text { Paper } \\
\text { ditemukan }\end{array}$ & $\begin{array}{c}\text { Paper } \\
\text { kandidat }\end{array}$ & $\begin{array}{c}\text { Paper } \\
\text { terpilih }\end{array}$ \\
\hline ACM & 59 & 15 & 5 \\
\hline
\end{tabular}




\begin{tabular}{lccc}
\hline $\begin{array}{l}\text { IEEE } \\
\text { Xplore }\end{array}$ & 398 & 42 & 8 \\
\hline MECS & 16 & 5 & 2 \\
\hline $\begin{array}{l}\text { Science } \\
\text { Direct }\end{array}$ & 64 & 8 & 1 \\
\hline $\begin{array}{l}\text { Springer } \\
\text { Link }\end{array}$ & 16 & 15 & 5 \\
\hline Total & 553 & 85 & 21 \\
\hline
\end{tabular}

\section{a. Distribusi Literatur}

Hasil pencarian literatur yang dipublikasikan pada 5 tahun terakhir menghasilkan 21 makalah untuk diteliti lebih lanjut. Gambar 3 memperlihatkan distribusi jumlah makalah, terjadi peningkatan di tahun 2019 namun kembali menurun di tahun 2020.

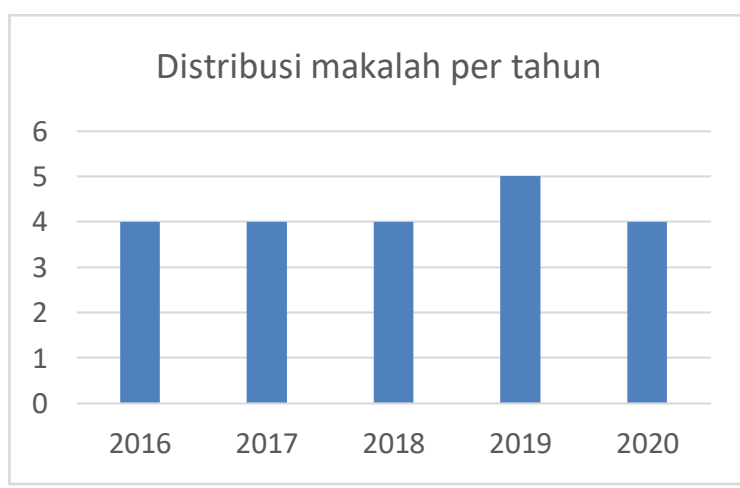

Gambar 3. Distribusi Makalah Per Tahun

\section{b. Pemilihan Makalah}

Tujuan dari penelitian ini adalah untuk mengetahui faktor apa saja yang dapat mempengaruhi proses implementasi smart education. Tabel 3 berisikan daftar referensi terpilih yang terkait dengan implementasi smart education.

Tabel 3. Sumber Literatur

\begin{tabular}{lllll}
\hline SID & \multicolumn{1}{c}{ Judul } & Sumber & Tahun & Jenis \\
\hline S1 & $\begin{array}{l}\text { Towards a Smart } \\
\text { Learning... [7] }\end{array}$ & ACM & 2016 & $\begin{array}{l}\text { Konferens } \\
\text { i }\end{array}$ \\
\hline
\end{tabular}

\begin{tabular}{|c|c|c|c|c|}
\hline S2 & $\begin{array}{l}\text { Measuring Smart } \\
\text { Education... [8] }\end{array}$ & $\mathrm{ACM}$ & 2018 & $\begin{array}{l}\text { Konferens } \\
\mathrm{i}\end{array}$ \\
\hline S3 & How Smart Are... [9] & $\mathrm{ACM}$ & 2019 & Jurnal \\
\hline S4 & $\begin{array}{l}\text { Smart School } \\
\text { Guidance... [10] }\end{array}$ & $\mathrm{ACM}$ & 2019 & $\begin{array}{l}\text { Konferens } \\
\mathrm{i}\end{array}$ \\
\hline S5 & The future of...[11] & $\mathrm{ACM}$ & 2020 & Konferens \\
\hline S6 & ICT and internet... [12] & 7 IEEEXp & 2016 & $\begin{array}{l}\text { Konferens } \\
\text { i }\end{array}$ \\
\hline S7 & Smart learning... [13] & IEEEXplore & 2016 & $\begin{array}{l}\text { Konferens } \\
\text { i }\end{array}$ \\
\hline S8 & $\begin{array}{l}\text { Edukas } \\
\text { environment...[14] }\end{array}$ & IEEEXplore & 2017 & $\begin{array}{l}\text { Konferens } \\
\mathrm{i}\end{array}$ \\
\hline S9 & $\begin{array}{l}\text { Smart education in } \\
\text { Yunnan... [15] }\end{array}$ & IEEEXplore & 2017 & $\begin{array}{l}\text { Konferens } \\
\mathrm{i}\end{array}$ \\
\hline S10 & The Knowledge... [16] & IEEEXplore & 2018 & $\begin{array}{l}\text { Konferens } \\
\text { i }\end{array}$ \\
\hline 11 & $\begin{array}{l}\text { Factors considered... } \\
\text { [17] }\end{array}$ & IEEEXplore & 2019 & $\begin{array}{l}\text { Konferens } \\
\mathrm{i}\end{array}$ \\
\hline 12 & Review on... [18] & IEEEXplore & 2019 & $\begin{array}{l}\text { Konferens } \\
\text { i }\end{array}$ \\
\hline S13 & $\begin{array}{l}\text { Smart Classroom... } \\
\text { [19] }\end{array}$ & IEEEXplore & 2019 & $\begin{array}{l}\text { Konferens } \\
\text { i }\end{array}$ \\
\hline 14 & Analyses of... [20] & MECS & 2018 & Jurnal \\
\hline S15 & $\begin{array}{l}\text { Rural Empowerment } \\
\text { [21] }\end{array}$ & MECS & 2020 & Jurnal \\
\hline S16 & Five trends of... [22] & Science Direct & 2020 & Jurnal \\
\hline S17 & $\begin{array}{l}\text { A research framework } \\
\text {... [5] }\end{array}$ & SpringerLink & 2016 & Jurnal \\
\hline S18 & $\begin{array}{l}\text { Citizen experiences... } \\
\text { [23] }\end{array}$ & SpringerLink & 2017 & Jurnal \\
\hline S19 & Smart learning... [24] & SpringerLink & 2017 & Jurnal \\
\hline S20 & Smart learn ... [25] & SpringerLink & 2018 & Jurnal \\
\hline & $\begin{array}{l}\text { Smart educational } \\
\text { tools... [26] }\end{array}$ & SpringerLink & 2020 & Jur \\
\hline
\end{tabular}

\section{c. Pemetaan Faktor}

Berdasarkan literatur yang berhasil dikumpulkan, selanjutnya dilakukan pemetaan pada masingmasing literatur terkait faktor apa saja yang perlu diperhatikan untuk mendukung kesuksesan implementasi konsep smart education. Hasil proses pemetaan dengan metode SLR menunjukkan berbagai faktor yang ditemukan, peneliti mengambil faktor yang telah dibahas 
pada lebih dari satu referensi. Pemetaan menghasilkan 17 faktor seperti pada Tabel 4.

Tabel 4. Pemetaan Faktor yang Berpengaruh dan Sumber Referensi

\begin{tabular}{|c|c|c|}
\hline FID & Faktor & Sumber referensi \\
\hline F1 & $\begin{array}{l}\text { Jaringan } \\
\text { Internet }\end{array}$ & $\begin{array}{l}\text { S1, S2, S3, S4, S5, S6, S7, } \\
\text { S8, S9, S10, S11, S12, } \\
\text { S13, S14, S15, S16, S17, } \\
\text { S18, S19, S20, S21 }\end{array}$ \\
\hline F2 & $\begin{array}{l}\text { Data } \\
\text { Server/Cloud } \\
\text { Computing }\end{array}$ & $\begin{array}{l}\text { S1, S2, S4, S5, S6, S7, S8, } \\
\text { S9, S12, S15, S17, S19, } \\
\text { S20, S21 }\end{array}$ \\
\hline F3 & $\begin{array}{l}\text { Perangkat } \\
\text { komunikasi }\end{array}$ & $\begin{array}{l}\text { S1, S2, S3, S4, S5, S6, S7, } \\
\text { S8, S9, S10, S11, S12, } \\
\text { S13, S14, S15, S16, S17, } \\
\text { S18, S19, S20, S21 }\end{array}$ \\
\hline F4 & $\begin{array}{l}\text { Ruang kelas } \\
\text { fisik }\end{array}$ & $\begin{array}{l}\text { S3, S4, S7, S9, S11, S12, } \\
\text { S13, S16, S17, S18, S19, } \\
\text { S20, S21 }\end{array}$ \\
\hline F5 & $\begin{array}{l}\text { Kelas Virtual (e- } \\
\text { Learning) }\end{array}$ & $\begin{array}{l}\text { S2, S4, S5, S6, S7, S8, S9, } \\
\text { S10, S11, S12, S16, S17, } \\
\text { S18, S19, S20, S21 }\end{array}$ \\
\hline F6 & $\begin{array}{l}\text { Tren } \\
\text { Teknologi/Aplik } \\
\text { asi }\end{array}$ & $\begin{array}{l}\text { S1, S2, S3, S4, S5, S6, S7, } \\
\text { S8, S9, S10, S11, S12, } \\
\text { S13, S14, S15, S16, S17, } \\
\text { S18, S19, S20, S21 }\end{array}$ \\
\hline F7 & $\begin{array}{l}\text { Sistem } \\
\text { pemantauan } \\
\text { (monitoring) } \\
\end{array}$ & $\begin{array}{l}\text { S5, S6, S7, S8, S13, S17, } \\
\text { S21 }\end{array}$ \\
\hline F8 & $\begin{array}{l}\text { Keamanan data } \\
\text { dan Privasi } \\
\text { pengguna }\end{array}$ & $\begin{array}{l}\text { S1, S2, S3, S5, S7, S8, } \\
\text { S12, S15, S16, S18, S21 }\end{array}$ \\
\hline F9 & $\begin{array}{l}\text { Integrasi data } \\
\text { dan aplikasi }\end{array}$ & $\begin{array}{l}\text { S1, S2, S4, S5, S7, S8, S9, } \\
\text { S10, S11, S12, S13, S14, } \\
\text { S15, S16, S17, S20, S21 }\end{array}$ \\
\hline F10 & $\begin{array}{l}\text { Sumber atau } \\
\text { materi } \\
\text { pembelajaran }\end{array}$ & $\begin{array}{l}\text { S3, S5, S6, S7, S8, S9, } \\
\text { S10, S11, S12, S13, S14, } \\
\text { S15, S16, S17, S18, S19, } \\
\text { S20, S21 }\end{array}$ \\
\hline F11 & $\begin{array}{l}\text { Pengajar (Guru, } \\
\text { Dosen, } \\
\text { Instruktur) }\end{array}$ & $\begin{array}{l}\text { S1, S2, S3, S4, S5, S6, S7, } \\
\text { S8, S9, S10, S11, S12, } \\
\text { S13, S14, S15, S16, S17, } \\
\text { S18, S19, S20, S21 }\end{array}$ \\
\hline F12 & Siswa & $\begin{array}{l}\text { S1, S2, S3, S4, S5, S6, } \\
\text { S7, S8, S9, S10, S11, } \\
\text { S12, S13, S14, S15, } \\
\text { S16, S17, S18, S19, } \\
\text { S20, S21 }\end{array}$ \\
\hline $\mathrm{F} 1$ & $\begin{array}{l}\text { Pengelola aplikasi } \\
\text { (admin, operator) }\end{array}$ & S1, S9, S15, S17, S21 \\
\hline
\end{tabular}

\begin{tabular}{lll}
\hline F14 & Model/framework & S1, S3, S5, S6, S7, S8, \\
& smart education & S9, S10, S12, S13, \\
& & S15, S16, S17, S18, \\
& & S19, S20, S21 \\
\hline F15 & Aturan dan & S1, S8, S9, S15, S16, \\
& kebijakan & S21 \\
\hline F16 & Silabus dan & S3, S8, S9, S10, S11, \\
& model & S12, S14, S15, S16, \\
& pembelajaran & S17, S18, S19, S20, \\
& & S21 \\
\hline F17 & Pembiayaan & S5, S7, S15, S16, S21 \\
\hline
\end{tabular}

Faktor-faktor yang ditemukan dapat dikategorikan ke dalam 5 aspek atau faktor utama, yaitu aspek teknologi, data, sumber daya manusia (SDM), tata kelola, dan pembiayaan. Gambar 5 menunjukkan aspek-aspek yang mempengaruhi implementasi smart education. Aspek teknologi terdiri dari 7 faktor pendukung, aspek data terdiri dari 3 faktor, aspek SDM terdiri dari 3 faktor, aspek tata kelola terdiri dari 3 faktor, sedangkan aspek pembiayaan hanya terdiri dari faktor pembiayaan saja.

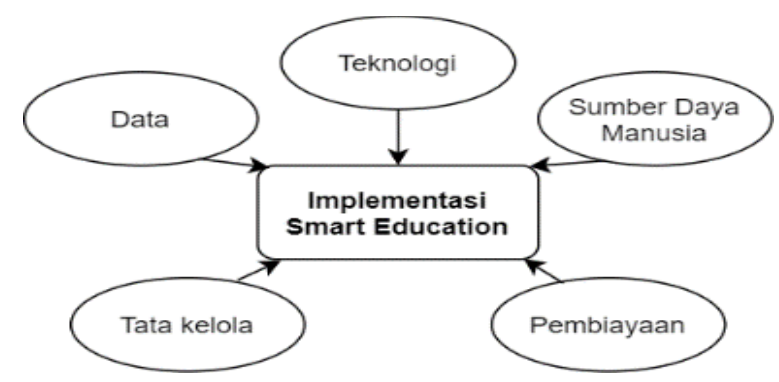

Gambar 5. Aspek yang Memengaruhi Implementasi Smart Education

Pemetaan kelima aspek atau faktor utama dan jumlah referensi yang membahas aspek tersebut ditunjukkan pada Tabel 5.

Tabel 5. Pemetaan Faktor Utama dan Jumlah Referensi

\begin{tabular}{ll}
\hline FID Faktor & $\begin{array}{l}\text { Jumlah } \\
\text { Referensi }\end{array}$ \\
\hline 1. Teknologi & \\
\hline
\end{tabular}




\begin{tabular}{llc}
\hline F1 & Jaringan Internet & 21 \\
\hline F2 & Data Server/Cloud Computing & 14 \\
\hline F3 & Perangkat komunikasi & 21 \\
\hline F4 & Ruang kelas fisik & 13 \\
\hline F5 & Kelas Virtual (e-Learning) & 16 \\
\hline F6 & Tren Teknologi/Aplikasi & 21 \\
\hline F7 & $\begin{array}{l}\text { Sistem pemantauan } \\
\text { (monitoring) }\end{array}$ & 7 \\
\hline 2. Data & 11 \\
\hline F8 & $\begin{array}{l}\text { Keamanan data dan Privasi } \\
\text { pengguna }\end{array}$ & 17 \\
\hline F9 & $\begin{array}{l}\text { Integrasi data dan aplikasi } \\
\text { F10 }\end{array}$ & $\begin{array}{l}\text { Sumber } \\
\text { pembelajaran }\end{array}$ \\
\hline 3. SDM & materi \\
\hline F11 & $\begin{array}{l}\text { Pengajar (Guru, } \\
\text { Instruktur) }\end{array}$ \\
\hline F12 & Pelajar (Siswa) & 21 \\
\hline F13 & $\begin{array}{l}\text { Pengelola aplikasi } \\
\text { operator) }\end{array}$ \\
\hline 4. Tata kelola \\
\hline F14 & $\begin{array}{l}\text { Model/framework smart } \\
\text { education }\end{array}$ \\
\hline F15 & Aturan dan kebijakan \\
\hline F16 & $\begin{array}{l}\text { Silabus dan model } \\
\text { pembelajaran }\end{array}$ \\
\hline 5. Finansial \\
\hline F17 & Keuangan/Pembiayaan \\
\hline
\end{tabular}

Pembahasan

Urutan pemeringkatan 17 faktor yang berpengaruh dari yang paling penting untuk diperhatikan atau paling banyak dibahas oleh sumber referensi ditunjukkan pada Gambar 6 .

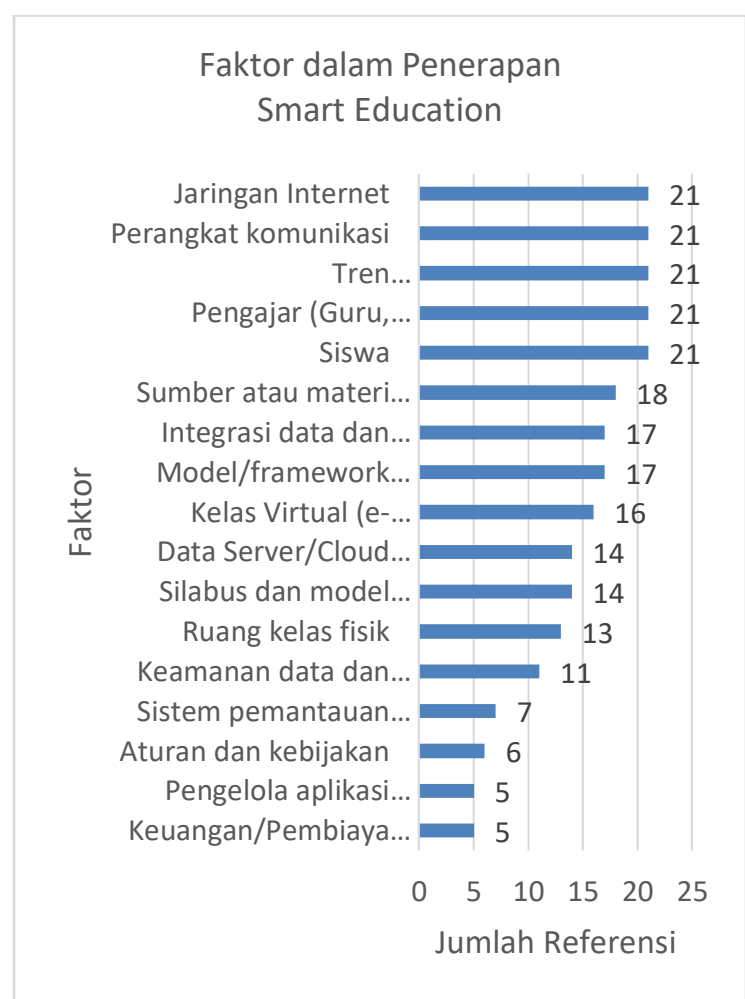

Gambar 6. Pemeringkatan Faktor-faktor yang Mempengaruhi Implementasi Smart Education

Berikut adalah penjelasan dari faktor-faktor yang berpengaruh dalam implementasi konsep smart education.

1. Teknologi.

Faktor-faktor yang terkait pemanfaatan teknologi untuk mendukung sistem pembelajaran.

a. Jaringan internet. Akses internet harus ada di seluruh wilayah implementasi untuk menghubungkan perangkat pengguna dengan server data.

b. Data Server/Cloud Computing. Pemanfaatan teknologi cloud computing dapat meningkatkan efisiensi dan efektivitas dalam proses penyimpanan data, karena 
segala perawatan dan pengamanan dapat dibantu oleh pihak penyedia.

c. Perangkat komunikasi. Berupa tablet, pc, laptop, smartphone, atau perangkat lainnya yang dapat digunakan untuk melakukan komunikasi dalam proses pembelajaran.

d. Ruang kelas/lab fisik. Ruang kelas ini berupa ruang pembelajaran yang dilengkapi fasilitas/media TIK, atau ruang laboratorium yang digunakan untuk praktikum.

e. Kelas Virtual. Merupakan suatu platform yang digunakan untuk melakukan proses pembelajaran, seperti e-learning atau teleconference. Kelas virtual ini berfungsi sebagai pelengkap pertemuan di kelas nyata, namun pada keadaan tertentu seperti saat pandemi covid-19 dapat difungsikan sebagai pengganti ruang kelas fisik.

f. Tren teknologi. Berupa platform atau aplikasi yang sudah menerapkan inovasi teknologi terbaru, seperti teleconference, big data analysis, gamification, artificial intelligence, dan lainnya.

g. Sistem pemantauan (monitoring), digunakan untuk mengawasi pengguna, melakukan evaluasi pembelajaran, dan mengantisipasi jika terjadi hal di luar perencanaan.

\section{Data}

Merupakan faktor yang terkait dengan data yang dibutuhkan pada proses pembelajaran. a. Keamanan data dan privasi pengguna, dapat menjadi masalah utama jika tidak dikelola dengan baik. Diantisipasi dengan penerapan single sign-on (SSO) atau mempercayakan pengembangan sistem dan penyimpanan data kepada penyedia yang sudah memiliki sertifikasi atau reputasi keamanan yang baik.

b. Integrasi data dan aplikasi. Pengajar/siswa dapat menggunakan platform pembelajaran dari berbagai perangkat seperti laptop, smartphone, dan tablet untuk mengakses data yang sama. Contoh manfaat lainnya ketika seorang siswa pindah sekolah, integrasi data akan memudahkan sekolah baru dalam mengakses data siswa yang sudah ada/diisi pada sekolah sebelumnya.

c. Sumber atau materi pembelajaran. Berupa materi belajar yang telah disusun oleh pengajar. Selain dari pengajar, siswa juga dapat mengakses materi sumber belajar digital lainnya dari internet.

\section{Sumber Daya Manusia}

Merupakan pihak yang terlibat dalam sistem pembelajaran.

a. Pengajar. Guru/dosen/instruktur merupakan pihak yang merancang silabus, penyampaian materi, dan mengevaluasi hasil pembelajaran. Pengajar harus menerapkan cara efektif dan inovatif dalam memanfaatkan teknologi. 
b. Pelajar/Siswa. Merupakan faktor yang menjadi sasaran utama dan penentu kesuksesan suatu sistem pendidikan. Perlu diperhatikan juga dukungan keluarga atau pemerintah terhadap fasilitas yang dibutuhkan oleh pelajar. Tidak hanya perangkat komunikasi, tetapi juga waktu, pengawasan, dan bimbingan dari orang tua.

c. Pengelola Aplikasi, merupakan penyedia, operator, atau pihak yang mengelola sistem dan layanan aplikasi pendidikan.

\section{Tata kelola}

Merupakan faktor yang terkait dengan tata kelola sistem pembelajaran.

a. Model/framework smart education. Penyusunan kerangka ini harus memperhatikan berbagai faktor dan dilakukan sebelum implementasi smart education. Dalam penelitian [5], terdapat tiga elemen utama yang harus ada pada model smart education, yaitu smart learning environment, smart pedagogies, dan smart learners.

b. Aturan dan kebijakan. Dukungan dan peran pemerintah yang dituangkan dalam aturan atau kebijakan akan menjadi modal awal implementasi smart education. Kebijakan harus melibatkan semua pemangku kepentingan yang terkait untuk menampung segala aspirasi dan meningkatkan peran aktif dari semua pihak. c. Silabus dan model pembelajaran, digunakan sebagai panduan pengajar dalam aktivitas pembelajaran. Strategi ini harus mencakup pembelajaran formal dan non-formal, baik secara luring maupun daring [5].

\section{Pembiayaan}

Pembiayaan merupakan unsur penting dalam implementasi, namun dalam penelitian yang dilakukan sebelumnya tidak semua referensi membahas tentang pembiayaan. Unsur pembiayaan ini tidak hanya mencakup biaya yang dikelola oleh pemerintah terkait pengembangan sistem dan implementasinya, tetapi juga biaya pemenuhan fasilitas/perangkat pendukung yang dibebankan kepada orang tua atau wali siswa.

\section{Kesimpulan}

Implementasi smart education diharapkan dapat meningkatkan kualitas sistem pendidikan di suatu daerah terutama di masa pandemi dan pasca pandemi covid-19. Sebelum mengimplementasikan smart education dalam suatu SPBE, pemerintah dan seluruh pihak yang terkait perlu memperhatikan beberapa hal yang nantinya dapat menjadi faktor penentu kesuksesan implementasi. Penelitian menggunakan metode Systematic Literature Review ini telah menyimpulkan beberapa hal terkait dengan faktor tersebut. Beberapa faktor 
yang perlu diperhatikan antara lain mencakup aspek: (i) teknologi, (ii) data, (iii) sumber daya manusia, (iv) tata kelola, dan (v) pembiayaan. Faktor-faktor tersebut merupakan rangkuman yang dapat dijadikan perhatian khusus bagi pemerintah dalam penerapan konsep smart education agar implementasi berjalan sukses.

Penelitian selanjutnya diharapkan dapat menggali lebih dalam mengenai masing-masing faktor yang berpengaruh, sehingga dapat menghasilkan gambaran lebih detail beserta dampak atau risiko dari setiap faktor tersebut.

\section{Daftar Pustaka}

[1] D. H. Jayani, "Risiko-risiko Masa Depan Pelajar Indonesia Pasca-Pandemi," katadata.co.id, 2021. [Online]. Available: https://katadata.co.id/ariayudhistira/analisisdata/ 608d1baf490ff/risiko-risiko-masa-depan-pelajarindonesia-pasca-pandemi. [Accessed: 23-Jun2021].

[2] S. Harijati, I. M. Sadjati, S. K. Handayani, and Dkk, Optimalisasi Peran Sains \& Teknologi untuk Mewujudkan Smart City. 2017.

[3] R. Yuliastri and H. Amani, "Indicators to Measure a Smart Building: An Indonesian Perspective," Int. J. Comput. Theory Eng., vol. 9, no. 6, pp. 406-411, 2017, doi: 10.7763/ijcte.2017.v9.1176.

[4] Perpres No 95, "Peraturan Presiden Nomor 95 Tahun 2018 tentang SPBE," 2018.

[5] Z.-T. Zhu, M.-H. Yu, and P. Riezebos, "A research framework of smart education," Smart Learn. Environ., vol. 3, no. 1, 2016, doi: 10.1186/s40561-016-0026-2.

[6] S. K. Boell and D. Cecez-Kecmanovic, "On being 'systematic' in literature reviews in IS," J. Inf. Technol., vol. 30, no. 2, pp. 161-173, 2015, doi: 10.1057/jit.2014.26.

[7] R. Hammad and D. Ludlow, "Towards a smart learning environment for smart city governance," Proc. - 9th IEEE/ACM Int. Conf. Util. Cloud
Comput. UCC 2016, pp. 185-190, 2016, doi: 10.1145/2996890.3007859.

[8] Indrawati, U. H. Ghassani, and H. Amani, "Measuring smart education readiness index: $A$ bandung perspective," ACM Int. Conf. Proceeding Ser., pp. 199-203, 2018, doi: 10.1145/3278252.3278277.

[9] M. K. Saini and N. Goel, "How smart are smart classrooms? A review of smart classroom technologies," ACM Comput. Surv., vol. 52, no. 6, 2019, doi: 10.1145/3365757.

[10] H. El Mrabet and A. A. Moussa, "Smart school guidance and vocational guidance system through the internet of things," ACM Int. Conf. Proceeding Ser., vol. Part F1481, 2019, doi: 10.1145/3320326.3320404.

[11] M. A. Amasha, M. F. Areed, S. Alkhalaf, R. A. Abougalala, S. M. Elatawy, and D. Khairy, "The future of using Internet of Things (IoTs) and Context-Aware Technology in E-learning," pp. 114-123, 2020, doi: 10.1145/3383923.3383970.

[12] M. Ur Rahman, Himanshi, V. Deep, and S. Rahman, "ICT and internet of things for creating smart learning environment for students at education institutes in India," Proc. 2016 6th Int. Conf. - Cloud Syst. Big Data Eng. Conflu. 2016, pp. 701-704, 2016, doi: 10.1109/CONFLUENCE.2016.7508209.

[13] M. Kadar, "Smart learning environment for the development of Smart City applications," 2016 IEEE 8th Int. Conf. Intell. Syst. IS 2016 - Proc., pp. 59-64, 2016, doi: 10.1109/IS.2016.7737500.

[14] F. Gaffo, G. Brigano, E. Gomede, R. Barros, and L. Mendes, "Edukas environment: Towards an integrated dashboard for education management in smart cities," 2017 IEEE SmartWorld Ubiquitous Intell. Comput. Adv. Trust. Comput. Scalable Comput. Commun. Cloud Big Data Comput. Internet People Smart City Innov. SmartWorld/SCALCOM/UIC/ATC/CBDCom/IOP ISCI 2017 - , pp. 1-8, 2018, doi: 10.1109/UICATC.2017.8397535.

[15] J. Tian and Z. Zheng, "Smart education in Yunnan, China: Present situation and construction measures," 14th Int. Conf. Serv. Syst. Serv. Manag. ICSSSM 2017 - Proc., 2017, doi: 10.1109/ICSSSM.2017.7996245.

[16] N. V. Dneprovskaya and I. V. Shevtsova, "The Knowledge Management System Development for Smart Education," Proc. 2018 Int. Conf. ' 
'Quality Manag. Transp. Inf. Secur. Inf. Technol. IT QM IS 2018, pp. 602-606, 2018, doi: 10.1109/ITMQIS.2018.8525129.

[17] J. Suwita, R. Kosala, B. Ranti, and S. H. Supangkat, "Factors considered for the success of the Massive Open Online Course in the era of Smart Education: Systematic Literature Review," Proceeding - 2019 Int. Conf. ICT Smart Soc. Innov. Transform. Towar. Smart Reg. ICISS 2019, pp. 0-4, 2019, doi: 10.1109/ICISS48059.2019.8969844.

[18] W. Shi et al., "Review on Development of Smart Education," Proc. - IEEE Int. Conf. Serv. Oper. Logist. Informatics 2019, SOLI 2019, pp. 157162 , 2019,

doi: 10.1109/SOLI48380.2019.8955052.

[19] A. R. Yuliantoputri, W. Muhamad, and S. Suhardi, "Smart Classroom Services System Design Based on Services Computing System," Proceeding - 2019 Int. Conf. ICT Smart Soc. Innov. Transform. Towar. Smart Reg. ICISS 2019, 2019 ,

doi: 10.1109/ICISS48059.2019.8969809.

[20] B. Fetaji, M. Fetaji, M. Ebibi, and S. Kera, "Analyses of Impacting Factors of ICT in Education Management: Case Study," Int. J. Mod. Educ. Comput. Sci., vol. 10, no. 2, pp. 2634, 2018, doi: 10.5815/ijmecs.2018.02.03.
[21] W. Yasya, "Rural empowerment through education: Case study of a learning community telecentre in Indonesia," Int. J. Mod. Educ. Comput. Sci., vol. 12, no. 4, pp. 12-26, 2020, doi: 10.5815/ijmecs.2020.04.02.

[22] N. C. Burbules, G. Fan, and P. Repp, "Geography and Sustainability Five trends of education and technology in a sustainable future," Geogr. Sustain., vol. 1, no. 2, pp. 93-97, 2020, doi: 10.1016/j.geosus.2020.05.001.

[23] R. Zhuang, S. Tang, J. Li, and R. Huang, "Citizen experiences of smart learning in China's cities," 2017, doi: 10.1186/s40561-017-0045-7.

[24] R. Zhuang, H. Fang, Y. Zhang, A. Lu, and R. Huang, "Smart learning environments for a smart city: from the perspective of lifelong and lifewide learning," Smart Learn. Environ., vol. 4, no. 1, 2017, doi: 10.1186/s40561-017-0044-8.

[25] J. Dron, "Smart learning environments, and not so smart learning environments: a systems view," 2018.

[26] R. P. R. Z. R. A. Ramirez-mendoza, "Smart educational tools and learning management systems :," Int. J. Interact. Des. Manuf., 2020, doi: 10.1007/s12008-020-00695-4. 